Journal of Social Sciences (COES\&RJ-JSS)

ISSN (E): 2305-9249 ISSN (P): 2305-9494

Publisher: Centre of Excellence for Scientific \& Research Journalism, COES\&RJ LLC

Online Publication Date: $1^{\text {st }}$ October 2017

Online Issue: Volume 6, Number 4, October 2017

DOI : $10.25255 /$ jss.2017.6.4.726.733

\title{
Never Deaf of Learning with Heart: Understanding the Essence of Handling Pupils with Hearing Impairment
}

\author{
Remedios M. Dela Rosa, Ferdinand C. Somido, Pedrito Jose V. Bermudo, \\ Ellen A. Salinas, Antonio R. Yango, Leomar S. Galicia
}

\begin{abstract}
:
This transcendental phenomenology study aimed at describing and understanding the lived experience of eight (8) Special education teachers handling learners with hearing impairment.Specifically, they were private school teachers in the cities of Biñan, Sta. Rosa and San Pedro Laguna, Philippines who were purposively selected using inclusion criteria. Framed with the approach of Moustakas (1994) as cited by Creswell (2007), the researchers carefully analyzed the participants' verbatim accounts which resulted in six (6) themes categorized into textural and structural descriptions. Collectively taken, the essence of the study highlighted the participants' experience in handling hearing-impaired learners which covered engaging them in different activities (Theme 1), customized communication with them (Theme 2), and love and drive to reach out to these individuals (Theme 3). They coped with the challenges they face by clinging to the vital role of assessment tools (Theme 4), highlighting values in teaching (Theme 5) and viewing their profession as a calling of commitment and devotion (Theme 6). The lived experiences of special education teachers with learners diagnosed with hearing impairment may serve as a feedback for special education instructional materials suppliers or developers in improving the contents of their works to better cater the needs of special education teachers in terms of the choice of innovated instructional materials that specifically address the learning needs of students in special education.
\end{abstract}

\section{Keywords:}

lived experience, special education teachers, learners with hearing impairment, phenomenological study

\section{Citation:}

Rosa, Remedios M.; Somido, Ferdinand C.; Bermudo, Pedrito, Jose V.; Salinas, Ellen A.; Yango, Antonio R.; Galicia, Leomar S. (2017); Never Deaf of Learning with Heart: Understanding the Essence of Handling Pupils with Hearing Impairment; Journal of Social Sciences (COES\&RJ-JSS), Vol.6, No.4, pp:726-733; $\quad$ DOI : 10.25255/jss.2017.6.4.726.733. 


\section{Introduction}

Hearing is what keeps us in touch with our world. It plays a significant role in expressing and receiving language. Hearing loss creates problems in how an individual expresses and receives language in turn causing social, communication, and educational problems (Hall, Oyer \& Haas, 2001). Educational managers therefore need to seriously consider the short and long term effects as well as far reaching consequences of how hearingimpairment affects a learner's ability to understand spoken language when developing their programs.

A special education program should be customized to address each individual student's unique needs. Special educators need to provide a continuum of services, in which learners with special needs receive varying degrees of support based on their individual needs. Also, it hastobe specifically tailored so that unique combination of needsof each learner is addressed.

Special education is the practice of educating students with special needs like with those who are mentally challenged, hearing impaired, or dyslexics, in a way that addresses their individual differences and needs. Ideally, this process involves the individually planned and systematically monitored arrangement of teaching procedures, adapted equipment and materials, and accessible settings.

From these premises, the researchers conducted this study with the view of understanding and describing the lived experience of Special Education (SPED)teachersof learners specifically diagnosed with hearing impairment. To solve the main problem, the following central problems were worked out by the researchers: 1) the lived experience of the participants being special education (SPED) teachers of learners with hearing impairment and 2) how the participants coped with the challenges of being special education (SPED) teachers of learners with hearing impairment.

As to significance, the findings of this study may direct school principals in providing both special education teachers with responsive instructional materials to further enhance the teaching strategies in their institutions. This may also help them in reassessing the needs for instructional materials in teaching special education in relation to the diverse profile of learners with special needs. This study could also serve as reference for SPED teachers to innovate their teaching skills and strategies in teaching special education students. The insights they may acquire from the lived experiences of the participants can be helpful in their respective context of teaching.They may also learn from their coeducators' exposure to the field which can make them have better understanding of similar or related experiences in teaching learners with hearing impairment. The lived experiences of special education teachers with learners diagnosed with hearing impairment may also serve as a feedback for special education instructional materials suppliers or developers in improving the contents of their works to better cater the needs of special education teachers in terms of the choice of innovated instructional materials that specifically address the learning needs of students in special education.

\section{Literature Review}

Hearing impairment (HI) is considered a hidden disability because it is not visible unlike other types of disabilities such as visual impairment or physical impairment which are clearly identifiable. HI or deafness is a condition where an individual is impaired in processing linguistic information through hearing. The severity of a hearing impairment is 
measured by the amount of sound that can be heard using one's better ear and this is measured using decibels (dB). According to World Health Organization (WHO, 2012), it is categorized into four, that is, mild hearing impairment where the minimum sound that can be heard is between 25 and $40 \mathrm{~dB}$, moderate hearing impairment where the minimum sound that can be heard is between 40 and $70 \mathrm{~dB}$, severe hearing impairment where the minimum sound that can be heard is between 70 and $95 \mathrm{~dB}$ and profound hearing impairment where the minimum sound heard is $95 \mathrm{~dB}$ and over. Hearing loss can be caused by a number of factors including; heredity (genetics), aging, loud sound exposure, diseases and infections, trauma (accidents), or ototoxic drugs (drugs and chemicals that are poisonous to auditory structures (Van and Dobie, 2004).

According to WHO (2012), there are 120 million people worldwide with hearing impairment, and 78 million of those affected are in developing countries. In the Philippines, it was found out that the prevalence of hearing impairment nationwide using the screening and functional assessment tools developed by the study was $2.04 \%$ while for hearing disability, results showed a $1.10 \%$ prevalence rate. In 1997 according to the Department of Health National Registry, hearing impairment was said to be $17 \%$ or 97,957 per 577,345. A similar survey in 1995 by the Philippine Consensus of population showed that prevalence rate of hearing diseases were estimated to be $12.55 \%$ or 115,357 per 919,292 individuals.

According to Muiti (2010): "the overall aim of education of children who are hearing impaired should be to make them well integrated happy hearing impaired individual and not a pale imitation of a hearing person. Their teachers aim should be to produce a happy well-adjusted hearingimpaired individual, each different from the other with his own personality. This calls for a greater commitment on the teachers" handling such children. A great deal of repetition is needed while teaching so that the children can grasp the teacher"s intended goals."

Badza and Chakuchichi (2000) state that the curriculum for the deaf and hard of hearing should include social skills and vocational skills. Education involves bringing up students into a social world in which they will participate. Like other forms of disability, lack of hearing imposes limitations on the individual's ability to acquire social skills, daily living skills, peer interaction, self-concept, grooming, toileting, dressing and so on. The deaf learn appropriate social behaviors only when they are deliberately sequenced into the curriculum since most social skills, moral and behaviors are transmitted through communication with other people (Northern and Downs, 2005).

\section{Methodology}

The researchers utilizedtranscendentalhhenomenology (also termed empirical, psychological) which was expounded by Moustakas (1994) who was cited by Creswell (2007). This research design focuses less on the interpretations of the researchers and more on a description of the experiences of the participants. The researchers used the procedures which consisted of identifying a phenomenon to study, bracketing one's experiences, and collecting data from several persons who have experienced the phenomenon. Furthermore, the data were analyzed by reducing the information into significant statements or quotes and then combining them into themes. Moreover, the researchers developed a textural description of the experiences of the participants (what they experienced) and a structural description of their experiences (how they experienced 
it in terms of the condition, situations or context). Lastly, a combination of the textural and structural descriptions was reported to convey the overall essence of the participants' experience, i.e. handling learners diagnosed with hearing impairment.

The researchers collected data through multiple and in-depth interviews with eight (8) individuals who have experienced teaching learners with hearing impairment. The hearing impaired learners under their tutelage were those with diagnosis between mild to severe hearing impairment based on the medical profile report in their schools.Specifically, they were private school teachers in the cities of Biñan, Sta. Rosa and San Pedro Laguna, Philippines. Inclusion criteria in selecting the participants included: 1) minimum of three years of experience in teaching learners with hearing impairment; 2) teaching learners who were diagnosed with hearing impairment as evidenced by their medical diagnosis report submitted to school's admission office; 3) graduated with special education degree; 4) licensed professional teachers as evidenced by the licensure examination identification card issued by the Professional Regulation Commission (PRC) of the Philippines; 5) signed the waiver for voluntary participation in the study. Meanwhile, secondary sources of date were culled from books and journals.

The researchers were the primary instrument in this qualitative study. They used a protocol that is predesigned form containing the research questions which are general and open-ended considering the guidelines of Moustakas (2004) as cited by Creswell (2007). Through the interview guide, the researchers were able to take notes during the interview about the responses of the participants. It also helped them organize thoughts on items such as headings, information about starting the interview, concluding ideas, information on ending the interview, and thanking the participants.

Authorization was sought from the Research Center of the University of Perpetual Help System Laguna, Philippinesin order to conduct the study and look intothe potential negative impact and risk to participants. A letter of communication was also secured from the school heads supervising the participating teachers.Consent was alsoobtained from the participants before they were included in the research investigation. The consent form contained: the right of the participants to voluntarily withdraw from the study at any time; the central purpose of the study and the procedures to be used in the data collection; comments about protecting the confidentiality of the respondents' shared accounts and their anonymity in the research report; a statement about known risks associated with the participation in the study; the expected benefits to accrue to the participants in the study; and the signature of the participants as well as the researcher (Creswell, 2007). Beforethe researchers conceptualized the essence of the study, they personally met again with the participants and gave hard copies of the interview verbatim transcription for them to check its accuracy. Also, the researchers gave them hard copies of the research report and expressed to them their gratitude for their participation in the study.

\section{Results and Discussion}

The study focused on the lived experience of teachers of Special Education (SPED) with learners diagnosed with hearing impairment. To solve the main problem, the following central problems were worked out by the researchers: 1) the lived experience of the participants being special education (SPED) teachers of pupils with hearing impairment and 2) how the participants coped with the challenges of being special education (SPED) teachers of pupils with hearing impairment. 
The significant statements that were based on the participants' verbatim responses in the interviews were thoroughly analyzed, outlined, and grouped into larger units of information called "meaningful units" or themes, a procedure called theme clustering.From these statements, the researchers were able to identify 6 theme clusters which were divided into two groups answering the twocentral questions of the study mentioned above.

\begin{tabular}{l} 
Six Theme Clusters Divided Into Two Groups \\
\hline Troup A: Textural Themes \\
Theme 1: Engaging hearing impaired pupils in different activities \\
Enchanting games that make them smile \\
Teaching them how to dance \\
Exposing them to educational tours \\
Theme 2: Communicating and dealing with hearing impaired pupils \\
Maturity level determines the level of difficulty in teaching them \\
Struggle in communicating with them \\
The challenge of using sign language \\
Dealing with different attitudes \\
Theme 3: Love for hearing-impaired learners \\
The drive to give them the opportunity to be successful in life \\
Passion and love for teaching \\
Group B: Structural Themes \\
Theme 4: Vital role of assessment tool \\
Observation \\
Cooperation \\
Comprehension \\
Theme 5: Values in everyday teaching \\
Practicing patience \\
Constant Interaction \\
Theme 6: A Calling \\
Fulfilling a commitment
\end{tabular}


1. As to the lived experience of the participants being special education (SPED) teachers of pupils with hearing impairment

Theme 1: Engaging hearing-impaired pupils in different activities. Letting hearingimpaired learners join activities like enchanting games that make them smile, dancing, and educational tours is one way of showing their abilities. Simple as they may seem, these shared experiences by the participants gave them a better understanding of their learners' needs.This is manifested through the following responses given by the participants:

(1) My most unforgettable moment was when I thought hearing impaired pupils on how to dance simple steps of folk dance. It is somehow difficult but challenging at the same time. It improves my skills in making techniques in how to communicate with pupils especially to those who are still young and are not yet familiar with sign language.

(2) One of the most unforgettable experiences as a teacher of children with hearing impairment is when they first joined the educational tour and all of them were smiling and very happy and excited to go to different places without their parents.

Theme 2: Communicating and dealing with hearing-impaired pupils. Dealing with hearing-impaired pupils is not easy. The participating teachers have to be equipped with proper communication skills through sign language. The most common difficulty that the participants faced is communicating with the pupils because there were many times when sign language is not enough to control their behavior, making the teachers to struggle in terms of their non-verbal communication with their learning-impaired pupils.

Theme 3: Love for Hearing-Impaired Learners. According to the participants, love is the best thing that they can give to their pupils with hearing impairment. As their teachers, they just don't focus on the learning challenge of learners with hearing impairment by accepting who they are and by touching their hearts as shown in a response below:

My love and passion for pupils with special needs is what keeps me into my profession. Knowing that there may be few people who understand them makes me more motivated as ateacher handling hearing-impaired learners.

2. As to how the participants coped with the challenges of being special education (SPED) teachers of pupils with hearing impairment

Theme 4: Vital role of assessment tool. Assessment is constantly necessary in order to monitor the changes or development in each pupil. Assessment and evaluation results reflect the learning of each learner. According to the participants, examinations, quizzes, recitation, observation and other assessment techniques should be constantly applied to measure learning performance.

Theme 5: Values in everyday teaching. What surfaced in this theme is the value of patience as a virtue, i.e. teachers should be able to exemplify values like kindness and work commitmentwhich are helpful in shaping and educating pupils with hearing impairment. This is evidenced in the following: 
(1) We value each learner by keeping in mind that they should be educated with love, understanding and respect.

(2) By continuously educating ourselves to understand their profile and needs and by practicing our profession with love and compassion.

Theme 6: A Calling. The participants shared that there are many forms of goals and dreams in life but in order to be satisfied, what they do must have a reason. To become teachers of hearing-impaired learners is a challenging task according to them so they always find the reason for each day they meet with their learners, .i.e.their passion to reach out to them. Their dedication to serve these individualsis a promised devotion that is driven by inspiration and a sense of fulfilling a commitment toothers, especially for the learners with special needs.

I ended up teaching learners who are hearing-impaired because I enjoyed it. Seeing them learn little by little gives me a sense of fulfillment as a teacher. It is challenging and sometimes overwhelming but it is fulfilling, heart-warming and a calling that's why I choose it for a reason, a reason to help with devotion and inspiration.

Essence. Through careful analysis of the details covered in the structural and textural descriptions, it is found that the participants' experience in handling hearing-impaired learners covered engaging them in different activities, customized communication with them, and love and drive to reach out to these individuals. They coped with the challenges they face by clinging to the vital role of assessment tools, highlighting values in teaching and viewing their profession as a calling of commitment and devotion.

\section{Future Directions}

Based on the findings of the study, the researchers recommend that special education teachers must continually undergo enrichment seminars and training to develop their teaching strategies for hearing- impaired learners. Teachers, classmates, and parents should be educated in communicating through sign language so learners with hearing impairment will not feel detached in terms of their communication. School administrators and managers should also look into highlighting constant collaboration with the parents of learners diagnosed with hearing impairment in order to scaffold the guidance and counseling program of the school that is specifically tailored to meet the diverse spectrum of needs of hearing-impaired learners. The local governmentof the Philippines should extend efforts in giving financial support that will helpmeet instructional needs and facilities of special education to ensure a successful instructional process for learners with special needs. A similar study may be conducted related to this investigation using different research design and with higher number of respondents.

\section{References}

Badza, A. \& Chakuchichi,D.D. (2000). Curriculum issues in disability and special education. Harare: Zimbabwe Open University.

Hall,B.J. Oyer, H.J. Haas, W.H. (2011). Speech, Language, and Hearing Disorders: A Guide for the Teacher. Allyn and Bacon: The University of Michigan.

Muiti, M.J. (2010). Hindrances to Effective Learning of Pupils with Hearing Impairment in Meru North District-Kenya. Retrieved September 11, 2017 from http://ir- 
Journal of Social Sciences (COES\&RJ-JSS), 6(4), pp. 726-733

library.ku.ac.ke/bitstream/handle/123456789/620/Muiti\%2C\%20Je nnifer.pdf?sequence $=3$

Northern, L.L. \& Downs, M.P. (2005). Hearing in children. Baltimore: Williams and Wilkins.

Van Hemel, S., and Dobie, R. A. (Eds.) (2004).Hearing Loss: Determining eligibility for social security benefits. National Academies Press. London.

WHO (2012).WHO global estimates on prevalence of hearing
loss.
Retrieved
September
12 ,

http://www.who.int/pbd/deafness/WHO_GE_HL.pdf

2017

from 